\title{
PENGARUH PERAMBANAN ECENG GONDOK (Eichhornia crassipes) OLEH IKAN KOAN (Ctenopharyngodon idella) TERHADAP KESUBURAN (N, P) DAN KELIMPAHAN FITOPLANKTON DI DANAU LIMBOTO
}

\author{
Krismono"), M. F. Rahardjo'), Enang Harris's), dan Endi Setiadi Kartamihardja ${ }^{3)}$ \\ 1) Peneliti pada Balai Riset Pemulihan Sumber Daya Ikan, Jatiluhur-Purwakarta \\ 2) Guru Besar pada Fakultas Perikanan dan Ilmu Kelautan-Institut Pertanian Bogor, Bogor \\ 3) Peneliti pada Pusat Riset Perikanan Tangkap, Ancol-Jakarta \\ Teregistrasi I tanggal: 21 Juli 2010; Diterima setelah perbaikan tanggal: 20 Juli 2010; \\ Disetujui terbit tanggal: 30 Juli 2010
}

\begin{abstract}
ABSTRAK
Pengendalian gulma air eceng gondok (Eichhornia crassipes) dengan ikan koan (Ctenopharyngodon idella) akan meningkatkan kesuburan perairan sebagai akibat sekresi dari ikan koan yang dikeluarkan di air. Penelitian mengenai pengaruh perambanan eceng gondok oleh ikan koan terhadap kesuburan perairan, N, P, dan kelimpahan fitoplankton di Danau Limboto perlu dilakukan. Penelitian ini bertujuan untuk mengkaji pengaruh perambanan ikan koan terhadap kesuburan perairan (N, P) dan kelimpahan fitoplankton di Danau Limboto. Metode penelitian dilakukan dengan percobaan menggunakan perlakuan pakan eceng gondok pada ikan koan. Rancangan percobaan dengan rancangan acak lengkap dengan tiga ulangan dan satu kontrol. Hasil penelitian menunjukan bahwa laju perambanan ikan koan dengan kepadatan 100, 200, dan 400 ekor dengan biomassa eceng gondok $10 \mathrm{~kg}$ mempengaruhi peningkatan produktivitas perairan atau kesuburan ( $\mathrm{N}$ dan $\mathrm{P}$ ) dan kelimpahan fitoplankton. Kepadatan ikan koan 200 ekor adalah kepadatan yang paling efektif untuk pengendalian eceng gondok dibanding kepadatan 100 dan 400 ekor.
\end{abstract}

KATAKUNCl: $\quad$ eceng gondok, ikan koan, kesuburan, perambanan, Danau Limboto

ABSTRACT: $\quad$ Effect of grazing rate of waterhyasinth by grass carp on nutien $(N, P)$ and fitoplankton abundance in Limboto Lake. By: Krismono, M. F. Rahardjo, Enang Harris, and Endi Setiadi Kartamihardja

To control of waterhyacinth (Eichhornia crassipes) using grass carp (Ctenopharyngodon idella) was fertilized in waters because of excresi of grass carp. The research is to knowed effect of grazing of grass carp to waterhyasinth to productivity and abundance of phytoplankton in Limboto Lake. Reseach Metodology is used experiment with rendom completed desaign with three treatmen with three replycation and one kontrol. The result each showed treatmen of stocking density 100, 200, 400 fish each cage, and fitoplankton abundance, stocking density 200 fish is cage increasing productivity, fitoplnkton abundance of lake. The treatmen stocking density 200 each cage Increased productivity of lake most effective to control waterhyacinth than stocking density 100 and 400 fish/cage.

\section{KEYWORDS: $\quad$ waterhyasinth, grass carp, productivity, grazing, Limboto Lake}

\section{PENDAHULUAN}

Danau Limboto di Provinsi Gorontalo sedang mengalami proses penuaan yang diindikasikan adanya sedimentasi dan pertumbuhan gulma air eceng gondok yang sangat pesat dan menutupi permukaan danau. Pertumbuhan gulma air eceng gondok di Danau Limboto pada tahun 1994 sudah menutupi permukaan air sekitar 35\% (Sarnita, 1994) dan penutupannya meningkat sampai $40 \%$ pada tahun 2004 (Hulinggi, 2005). Pada tahun 2008 penutupan eceng gondok di perairan Danau Limboto meningkat mencapai sekitar $40-60 \%$ luas permukaan danau. Perkembangan gulma eceng gondok yang pesat tersebut telah menimbulkan berbagai perubahan pada ekosistem perairan antara lain penurunan mutu kualitas air karena serasah daun eceng gondok (Allelopati), tekanan terhadap populasi ikan dan plankton dan pendangkalan karena evaporasi pada permukaan air yang tertutup oleh gulma air eceng gondok mempunyai kecepatan evaporasi dari permukaan yang tertutup eceng gondok tiga kali lebih cepat dibandingkan dengan permukaan perairan yang terbuka (Penfaund \& Early, 1948). Untuk mempertahankan ekosistem perairan Danau Limboto sebagai cadangan air, penahan banjir, dan tempat usaha perikanan diperlukan langkah-langkah penyelamatan atau rehabilitasi danau yakni antara lain dengan mengendalikan populasi gulma air eceng gondok. Pengendalian secara biologis menggunakan ikan koan adalah cara yang terbaik karena tidak 
mengganggu ekologi perairan dan ekonomis (El Samman \& El Ella, 2006). Ikan koan merupakan jenis ikan yang paling efektif digunakan untuk mengendalikan populasi eceng gondok (Soeryani, 1982; Ryding \& Rast,1989; Opuszynski \& Shireman,1995; Petr, 2000; Hartoto et al., 2001; Hickley \& Harper, 2002; Bonar et al., 2002; Pokorny \& Kvet, 2004; Cudmore et al., 2004; Pipalova, 2006; Gardner, 2008). Dampak dari perambanan ikan terhadap eceng gondok mempengaruhi sedimen, bahan organik total, kualitas air dan fitoplankton (Pipalova, 2006). Menurut Moss et al. (2002) makrofita di perairan berdampak langsung terhadap lingkungan perairan di sekitarnya yaitu Allelopati, kompetisi N dengan fitoplankton, penurunan intensitas cahaya, serta denitrifikasi detritus. Dampak tidak langsung di antaranya predator besar kelompok herbivora, khususnya dalam dominansi pemanfaatan sumber daya pakan, fitoplankton bila ada penumpukan nutrien, nitrat $\left(\mathrm{N}-\mathrm{NO}_{3}\right)$, dan amonium $\left(\mathrm{N}-\mathrm{NH}_{4}\right)$.

Penelitian tentang pengaruh perambanan ikan koan terhadap kesuburan perairan, (N, P) dan kelimpahan fitoplankton di Danau Limboto perlu dilakukan untuk menjaga produksi sumber daya perikanan supaya lestari dan berkelanjutan. Penelitian ini bertujuan untuk mengkaji dampak perambanan eceng gondok oleh ikan koan terhadap kesuburan perairan, kelimpahan plankton, dan produktivitas perairan.

\section{BAHAN DAN METODE}

\section{Bahan}

1. Eceng gondok diambil dari perairan Danau Limboto di wilayah Desa lluta atau di lokasi yang digunakan untuk penelitian. Eceng gondok dipilih yang mempunyai ukuran bobot dan morfologi sama atau seragam.

2. Benih ikan berasal dari Balai Besar Budi Daya Ikan Air Tawar Sukabumi yang telah diadaptasikan di Danau Limboto selama enam bulan, dengan ukuran 8-15 g/ekor.

3. Kurungan dari bahan waring warna hitam dengan ukuran $(4 \times 4 \times 2,4) \mathrm{m}^{3}$, sebanyak 12 buah, dan mata jaring $3 \mathrm{~mm}$.

\section{Metode}

\section{Lokasi penelitian}

Penelitian ini bersifat percobaan lapangan dilakukan di daerah budi daya perairan Danau Limboto, wilayah Desa lluta yang terletak di Kecamatan Batudaa, Kabupaten Gorontalo, Provinsi Gorontalo (Gambar 1).

Penelitian ini dilakukan pada bulan Nopember 2009 sampai Pebruari 2010. Ikan koan dengan pakan 10 $\mathrm{kg}$ eceng gondok hidup.

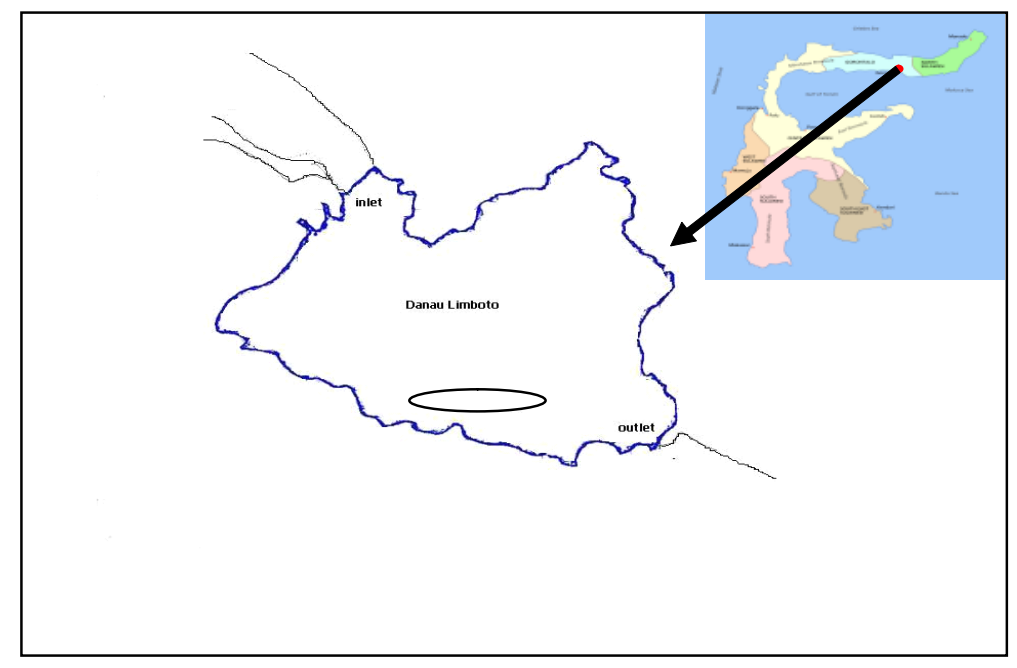

Gambar 1. Lokasi penelitian di Danau Limboto, Desa lluta, Kecamatan Batudaa, Kabupaten Gorontalo, Provinsi Gorontalo.

Figure 1. Reseach location at Limboto Lake.

Keterangan/Remarks: $\longrightarrow$ Lokasi penelitian 


\section{Rancangan percobaan}

Percobaan lapangan menggunakan rancangan acak lengkap dengan tiga perlakuan dan tiga ulangan (3x3), perlakuannya adalah biomassa atau padat tebar ikan yaitu:

A $=1 \mathrm{~kg} / 100$ ekor ikan koan dengan pakan $10 \mathrm{~kg}$ eceng gondok hidup.

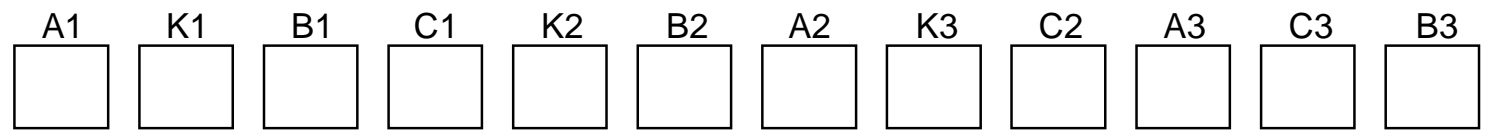

Gambar 2. Tata letak perlakuan penelitian.

Figure 2. Research desaign.

Keterangan/Remarks:

$\mathrm{A}=$ padat tebar 100 ekor ikan koan dengan pakan $10 \mathrm{~kg}$ eceng gondok hidup.

$\mathrm{B} \quad=$ padat tebar 200 eko ikan koan dengan pakan $10 \mathrm{~kg}$ eceng gondok hidup.

$\mathrm{C}=$ padat tebar 400 ekor ikan koan dengan pakan $10 \mathrm{~kg}$ eceng gondok hidup.

$\mathrm{K}=$ kontrol tanpa ikan ikan koan dengan pakan $10 \mathrm{~kg}$ eceng gondok hidup.

1, 2, 3 = ulangan

\section{Konstruksi unit eksperimen}

Untuk eksperimen dibuat kurungan dari bahan waring polyethilene dengan ukuran panjang $\mathrm{x}$ lebar $\mathrm{x}$ tinggi $=4 \times 4 \times 2,4 \mathrm{~m}^{3}$, di tengahnya diberi tempat untuk eceng gondok yang diletakan dalam kotak bambu dengan ukuran $2 \times 2 \mathrm{~m}$ dan diikat dengan tambang supaya terletak di tengah kurungan.

\section{Parameter yang diukur}

Parameter yang diukur selama penelitian meliputi kualitas air yang ditera adalah suhu $(\mathrm{T})$, kecerahan, kedalaman, oksigen terlarut (DO), $\mathrm{pH}$, nitrat $\left(\mathrm{NO}_{3}\right)$, amonium $\left(\mathrm{NH}_{3}\right)$, ortofosfat $\left(\mathrm{PO}^{3-}\right)$, dan bahan organik total (TOM). Hasil analisis parameter tersebut kemudian digunakan untuk menentukan variabel kerja yang meliputi kesuburan perairan, ratio N/P, dan DO minimum adalah $\mathrm{DO}$ terendah pada pengamatan 24 jam, $\mathrm{DO}_{\text {maksimum }}\left(\mathrm{DO}_{\text {tertinggi }}\right)$ dan defleksi $\mathrm{DO}\left(\mathrm{mgO}_{2} \mathrm{~L}^{\mathrm{L}} \mathrm{jam}-\right.$ $\left.{ }^{1}\right)=\left(\mathrm{DO}_{\text {maksimum }} \mathrm{Do}_{\text {minimum }}\right) / \mathrm{t}$. Kecerahan perairan untuk menentukan kedalaman daerah eufotik (Zeu=2,71 $\mathrm{x}$ tingkat kecerahan air (Poole \& Atkins, 1929 dalam Lembaga IImu Pengetahuan Indonesia, 1991). Parameter, metode analisis, dan alat pengukuran kualitas air tertera pada Tabel 1.

Tabel 1. Parameter, metode, dan alat pengamatan kualitas air

Table 1. Parameters, method, and waters quality equipments

\begin{tabular}{|c|c|c|c|c|}
\hline No. & $\begin{array}{l}\text { Parameter yang diamati/ } \\
\text { Parameters observed }\end{array}$ & Satuan/Unit & Metode/Method & Alat/Equipments \\
\hline & Parameter fisika & & & \\
\hline 1. & Kecerahan & $\mathrm{cm}$ & Insitu & Secchi disk \\
\hline 2. & Suhu air & ${ }^{\circ} \mathrm{C}$ & Insitu & Termometer \\
\hline 3. & $\begin{array}{l}\text { Kedalaman air } \\
\text { Parameter kimia }\end{array}$ & $M$ & Insitu & Meteran \\
\hline 1. & $\mathrm{pH}$ & & Insitu & $\mathrm{pH}$ indicator \\
\hline 2. & Oksigen terlarut & $\mathrm{mg} / \mathrm{L}$ & Winkler & Titrasi, Natrium tiosulfat \\
\hline 3. & $\mathrm{~N}-\mathrm{NH}_{4}$ & $\mathrm{mg} / \mathrm{L}$ & Nessler & Spektrofotometer \\
\hline 4. & $\mathrm{P}-\mathrm{PO}_{4}$ & $\mathrm{mg} / \mathrm{L}$ & Stannus Chloride & Spektrofotometer \\
\hline 5. & Klorofil-a & $\mathrm{mg} / \mathrm{m}^{3}$ & Tricometric & Spectrofotometer \\
\hline 6. & Fitoplankton & $\mathrm{sel} / \mathrm{L}$ & Insitu & Net plankton (40um) \\
\hline \multirow{5}{*}{8.} & Paniang & $\mathrm{Mm}$ & Insitu & Califer \\
\hline & Bobot & $g$ & Insitu & Timbangan digital $(0,1 \mathrm{~g})$ \\
\hline & Eceng gondok & & & \\
\hline & Bobot & $\mathrm{kg}$ & Insitu & Timbangan gantung $(1 \mathrm{~kg})$ \\
\hline & Luas tutupan & $\mathrm{m}^{2}$ & Insitu & Meteran gulung \\
\hline
\end{tabular}




\section{Analisis data}

1. Eceng gondok yang ditera adalah bobot eceng gondok.

2. Ikan koan yang ditera adalah ukuran bobot, panjang, dan jumlah kematian.

Data variabel ikan koan kemudian digunakan untuk menghitung laju pertumbuhan ikan koan dengan formula sebagai berikut:

$$
\left(W_{t}=W_{0} e^{k t}\right)
$$

Sintasan $\left(\mathrm{SR}=\mathrm{N}_{\mathrm{t}} / \mathrm{N}_{\mathrm{to}} \times 100 \%\right)$

Mortalitas $\left[M R=\left\{\left(\operatorname{lnN} N_{t}-\ln N_{o}\right) / t x 100 \%\right\}\right]$

Bobot rata-rata ikan koan $\left(\mathrm{U}_{\mathrm{B}} \mathrm{B}_{\mathrm{t}} / \mathrm{N}_{\mathrm{t}}\right)$

Biomassa ikan koan ( $\mathrm{B}=\mathrm{Sr} r u)$

di mana:

WO = bobot individu ikan koan pada hari ke-0 (g/ ekor)

$\mathrm{Wt}$ = bobot individu ikan koan pada hari ke-t $(\mathrm{g} /$ ekor)

$\mathrm{t}=$ bobot rata-rata ikan koan $(\mathrm{g})$

NO = jumlah ikan koan pada hari ke-0 (ekor)

$\mathrm{Nt}=$ jumlah ikan koan pada hari ke-0 (ekor)

$\mathrm{SR}=\operatorname{sintasan}(\%)$

$\mathrm{MR}$ = laju mortalitas

$\mathrm{B}=$ biomassa ikan koan

Kelimpahan fitoplankton dihitung dengan menggunakan metode Lackey Drop Microtransect Counting (American Public Health Association, 2005) dengan persamaan sebagai berikut:

$(\mathrm{N}=\mathrm{n} \times \mathrm{A} / \mathrm{B} \times \mathrm{C} / \mathrm{D} \times 1 / \mathrm{E})$ $(6$

di mana:

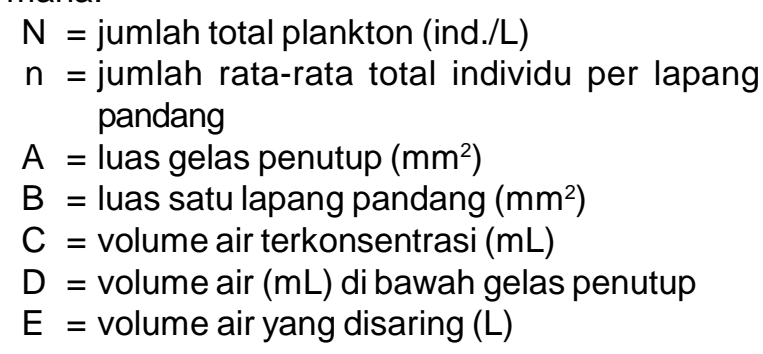

Produktivitas perairan dihitung dengan botol gelap botol terang (Almazan \& Boyd ,1978):

$$
\begin{array}{r}
\mathrm{GP}=\left(\underline{\mathrm{O}}_{2} \frac{\mathrm{BT}-\mathrm{O}_{2}}{\mathrm{BG})} 0,3125\right) \\
\text { lamancahayaan (jam) }
\end{array}
$$

di mana:

$$
\begin{aligned}
& \mathrm{GP}=\text { produktivitas primer kotor }(\mathrm{mg} / \mathrm{L} / \mathrm{jam}) \\
& \mathrm{BT}=\text { botol terang }\left(\mathrm{mg} / \mathrm{L} \mathrm{O}_{2}\right) \\
& \mathrm{BG}=\text { botol gelap }\left(\mathrm{mg} / \mathrm{L} \mathrm{O}_{2}\right)
\end{aligned}
$$

Untuk analisis klorofil-a dengan metode tricometri dan menggunakan formulasi dari Wetzel (2001) sebagai berikut:

$$
\begin{aligned}
& \text { Klorofil-a }\left(\mathrm{mg} / \mathrm{m}^{3}\right)=\frac{\text { Ca } \times \text { Volume Ekstrak }}{\text { Volume contoh } \times \mathrm{d}} . . \text { (8 } \\
& \mathrm{Ca}=11,85(\mathrm{OD} 664)-1,54 \text { (OD647)-0,08 (OD630). (9 }
\end{aligned}
$$

di mana:

$\mathrm{Ca}$

$=$ konsentrasi klorofil-a dalam ekstrak (mg/L)

Volume ekstrak = volume contoh setelah dilarutkan dalam aseton

Volume contoh = volume air yang disaring (L)
d
$=$ diameter atau celah kuvet yang digunakan (cm)

OD664,OD647, OD630 = absorban yang diperiksa (celah cahaya $1 \mathrm{~cm}$ )

pada setiap panjang gelombang setelah dikurangi dengan absorban pada panjang gelombang $750 \mathrm{~nm}$.

Analisis hubungan laju perambanan eceng gondok menggunakan metode Lodka-Voltera dalam (Crawley, 1983) sebagai berikut:

$$
\frac{\mathrm{dV}}{\mathrm{dt}}=\frac{\mathrm{aV}(\mathrm{K}-\mathrm{V}) / \mathrm{K}}{\mathrm{K}}-\mathrm{b} \mathrm{NV}
$$

$\frac{\mathrm{dV}}{\mathrm{dt}}=\mathrm{cNV}-\mathrm{dN}$

di mana:

$\underline{\mathrm{dV}}$ = perubahan rata-rata kelimpahan tumbuhan

$\mathrm{dt} \quad$ (eceng gondok)

$\mathrm{V}=$ kelimpahan tumbuhan

$\mathrm{K}$ = daya dukung (carrying capacity)

$\mathrm{NV}$ = perubahan rata-rata kelimpahan herbivora

a = variabel kelimpahan tumbuhan

$\mathrm{b}=$ variabel tingkat kematian tumbuhan

$\underline{\mathrm{V}}=$ perubahan rata-rata kelimpahan herbivora

$\mathrm{dt}$ (ikan koan)

$\mathrm{NV}=$ pertambahan herbivora

$\mathrm{N}=$ kelimpahan herbivora

c = variabel kelimpahan tumbuhan

$\mathrm{d}=$ variabel tingkat kematian herbivora 
Untuk mengetahui hubungan antar variabel laju pertumbuhan ikan, perambanan ikan koan terhadap eceng gondok menggunakan regresi linear. Dihitung dengan menggunakan paket Software Minitab Versi 14 Programme.

\section{HASIL DAN BAHASAN}

\section{Laju Perambanan}

Laju perambanan ikan koan terhadap eceng gondok selama 60 hari tidak berbeda nyata $(p>0,05)$ (Gambar 2 dan Lampiran 1) dengan padat tebar ikan koan 100, 200, dan 400 ekor masing-masing 112,9; 135,8; dan $187 \mathrm{~g}$ atau 1,8; 2,2; dan 3,1 g/hari. Laju perambanan selama penelitian mengalami penurunan setelah hari ke-10 sampai 40, kemudian meningkat lagi sampai hari ke-50, dan turun sampai hari ke-60. Hal ini berhubungan dengan preferensi ikan koan lebih suka makan filamen yang lunak yaitu akar eceng gondok (Gardner, 2008), sesudah habis selanjutnya baru batang dan daun yang lebih sulit dicerna, sehingga laju perambanan menurun.

\section{Laju Pertumbuhan Ikan}

Laju pertumbuhan ikan koan (Gambar 3) yang ditebar dengan padat tebar 100 ekor $(0,53 \mathrm{~g} / \mathrm{hari})$ berbeda nyata lebih kecil dibanding dengan padat tebar 200 ekor (1,13 g/hari) dan 400 ekor $(1,26 \mathrm{~g} /$ hari) dari hasil perhitungan analisis sidik ragam berbeda nyata (Lampiran 2), sedangkan laju pertumbuhan antara padat tebar 200 dan 400 ekor dapat disebut sama $(P>0,05)$.

Produksi individu ikan dengan padat tebar 100 , 200, dan 400 ekor masing-masing 32, 68, dan $76 \mathrm{~g}$, sedangkan faktor konversi pakan (FCR) pada masingmasing kepadatan 3,$5 ; 1,99$; dan 2,46. Kematian (mortalitas) ikan koan selama penelitian 60 hari pada kepadatan 100, 200, dan 400 ekor masing-masing 5, 15 , dan $18,5 \%$.

Hasil penelitian ini menunjukan bahwa ikan koan dapat merubah energi dari eceng gondok menjadi daging ikan. Perubahan energi tersebut yang paling efektif adalah dengan FCR paling kecil $(1,99)$ adalah pada perlakuan pada padat tebar 200 ekor.

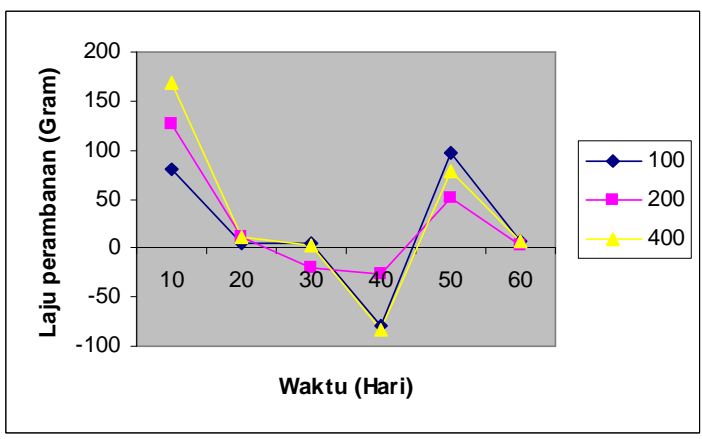

Gambar 2. Laju perambanan ikan koan terhadap eceng gondok. Figure 2. Grazing rate of grasscarp to Eichhornia crassipes.

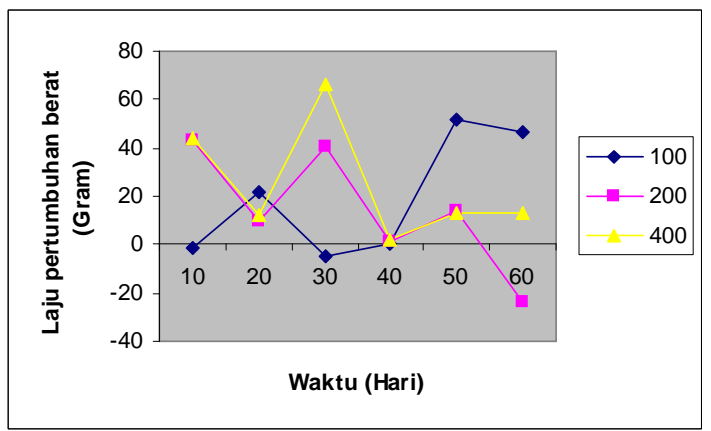

Gambar 3. Laju pertumbuhan bobot ikan koan.

Figure 3. Growth rate of grasscarp. 


\section{Kesuburan Perairan (N dan $\mathrm{P}$ ), Kelimpahan Plankton dan Produktivitas Perairan}

\section{Kandungan $\mathrm{N}-\mathrm{NH}_{4}$ di perairan}

Kandungan amonium pada perlakuan padat tebar ikan koan 100 dan 400 ekor pada hari ke-10 sampai 30 secara nyata berbeda dengan padat tebar ikan koan 200 ekor dan kontrol tanpa ikan (Gambar 4). Kandungan amonium pada perlakuan padat tebar ikan koan 100 ekor lebih tinggi sedangkan pada padat tebar ikan koan 400 ekor lebih rendah.

\section{Kandungan ortofosfat $\left(\mathrm{P}-\mathrm{PO}_{4}\right)$ di perairan}

Kandungan ortofosfat di kurungan ikan dengan kepadatan ikan koan 200 ekor langsung meningkat pada hari ke-10 sampai 30 dan kemudian kembali seperti pada awal, untuk kepadatan ikan koan 100 ekor meningkat pada hari ke-30 sampai 50 dan kembali normal, sedangkan kepadatan ikan koan 400 ekor relatif stabil (Gambar 5). Peningkatan ortofosfat berdampak positif meningkatkan kelimpahan fitoplankton pada kepadatan 200 ekor dan tidak terjadi pada kepadatan 100 serta 400 ekor (Gambar 6).

Pengaruh perambanan pada kualitas air dapat meningkatkan amonium dan ortofosfat. Keadaan tersebut dapat dilihat bila dibandingkan dengan kandungan amonium dan ortofosfat kontrol pada Gambar 4 dan 5.

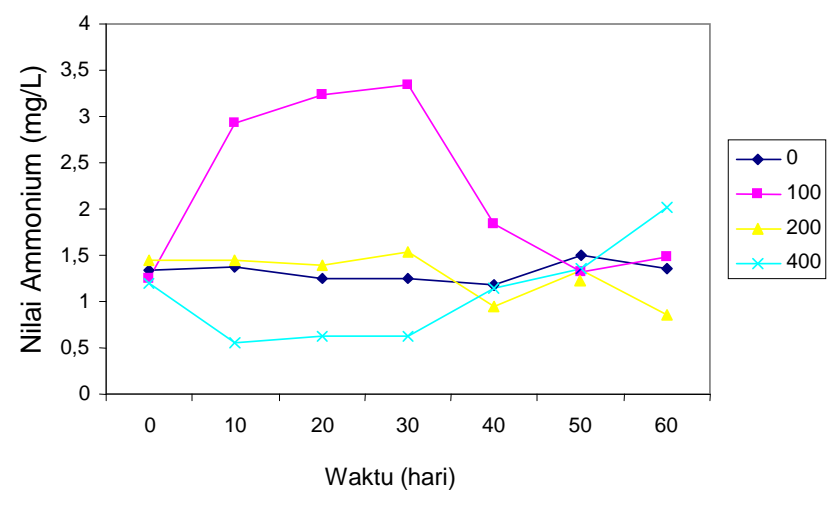

Gambar 4. Kandungan ammonium di perairan selama penelitian.

Figure 4. Concentrasi of amonium during observation.

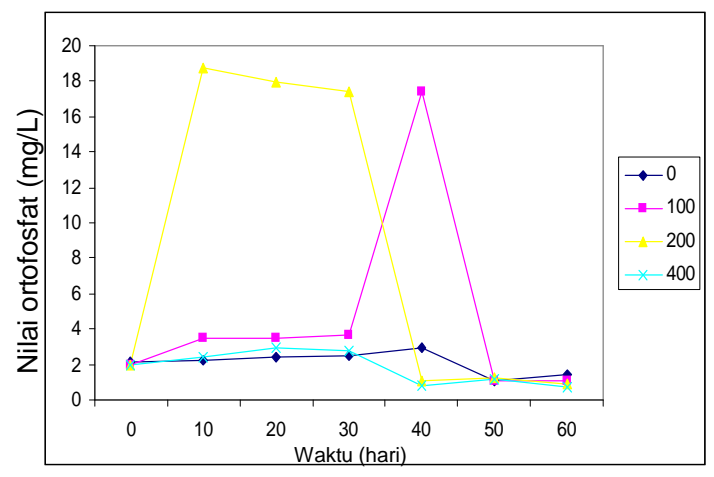

\section{Gambar 5.}

Kandungan $\mathrm{P}$ (ortofosfat) di perairan selama penelitian.

Figure 5. Concentration of ortophosphat (P-PO4).

\section{Kelimpahan fitoplankton}

Kelimpahan fitoplankton pada padat tebar ikan koan 100 ekor menurun selama penelitian, pada padat tebar 200 ekor relatif stabil dan untuk 400 ekor menurun pada awal sampai hari ke-20 dan kemudian meningkat kembali pada hari ke-40 (Gambar 6).
Kondisi ini dipengaruhi oleh adanya kandungan ortofosfat diperairan (Gambar 5) pada perlakuan padat tebar ikan koan 400 ekor konsentrasinya menurun sedangkan kepadatan 200 ekor konsentrasinya ortofosfat meningkat kemudian stabil setelah hari ke-40. Sedangkan kondisi populasi fitoplankton antar perlakuan dibandingkan kontrol menunjukan 
penurunan pada perlakuan padat tebar 100, 200, dan 400 ekor makin mengecil populasinya (Gambar 7). Hal ini disebabkan karena makin besar padat tebar, maka ekskresinya makin besar dan mempengaruhi kualitas air serta pertumbuhan fitoplankton.

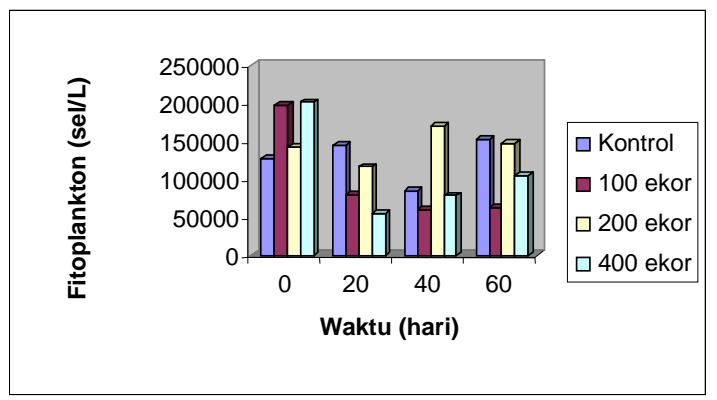

Gambar 6.

Kelimpahan fitoplankton selama penelitian.

Figure 6. Abaundance of fitoplankton, during observation.

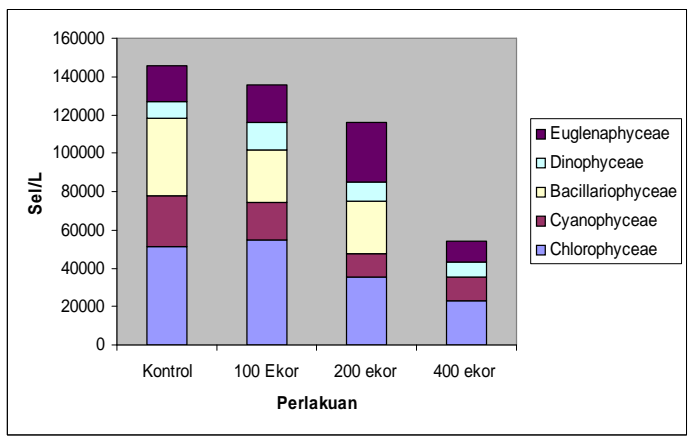

Gambar 7.

Kelimpahan fitoplankton pada masing-masing perlakuan.

Figure 7. Abundance of fitoplankton on each treatmen.

\section{Produktivitas perairan}

Produktivitas perairan berdasarkan atas biomassa klorofil-a pada perlakuan padat tebar ikan koan 400 ekor lebih besar dibanding perlakuan padat tebar 100 ekor, sedangkan kepadatan 200 ekor dan kontrol tanpa ikan yang relatif sama (Gambar 8). Hal ini sesuai dengan kelimpahan fitoplankton (Gambar 6) karena klorofil-a diukur dari kelimpahan populasi fitoplankton di perairan. Produktivitas perairan juga dapat dihubungkan dengan besarnya bukaan penutupan eceng gondok di permukaan perairan, maka pada perlakuan 200 dan 400 ekor ikan koan luas pembukaan eceng gondok lebih besar dibanding padat tebar 100 ekor. Hal tersebut di atas mengakibatkan proses fotosintesis yang terjadi lebih besar sehingga mendorong pertambahan fitoplankton, pada perlakuan kepadatan 200 dan 400 ekor produktivitas perairan lebih besar dibanding 100 ekor.

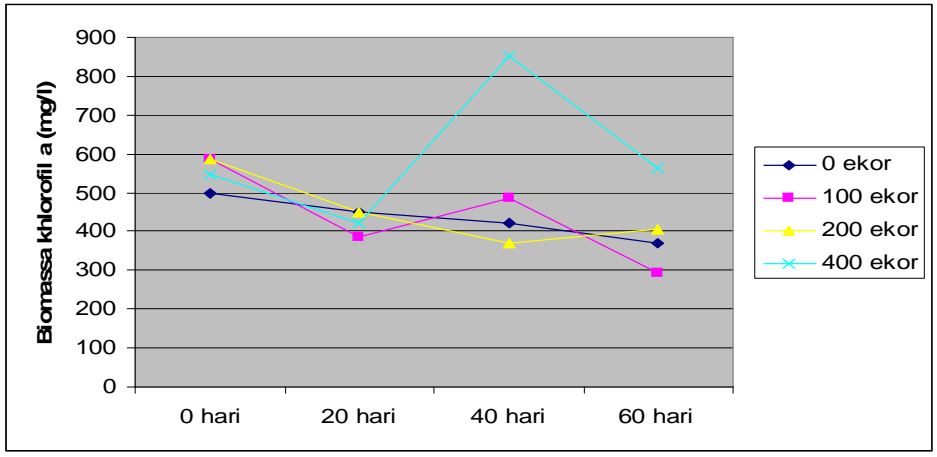

Gambar 8.

Produksi biomassa perairan (klorofil-a) selama penelitian.

Figure 8. Biomassa productivity in waters during observation. 
Produktivitas primer berdasarkan atas kandungan oksigen, terjadi penurunan sejak awal pada hari ke20 kemudian naik pada hari ke-50 dan 60 (Gambar 9), hal ini mungkin disebabkan karena adanya sekresi pakan yang memerlukan oksigen untuk proses dekomposisi. Kondisi tersebut sesuai dengan kandungan oksigen terlarut di perairan (Gambar 10).

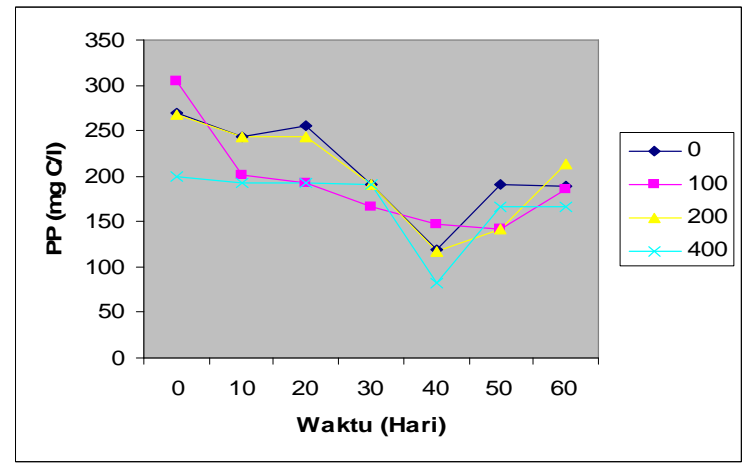

Gambar 9. Produktivitas primer perairan selama penelitian.

Figure 9. Primer productivity during observation.

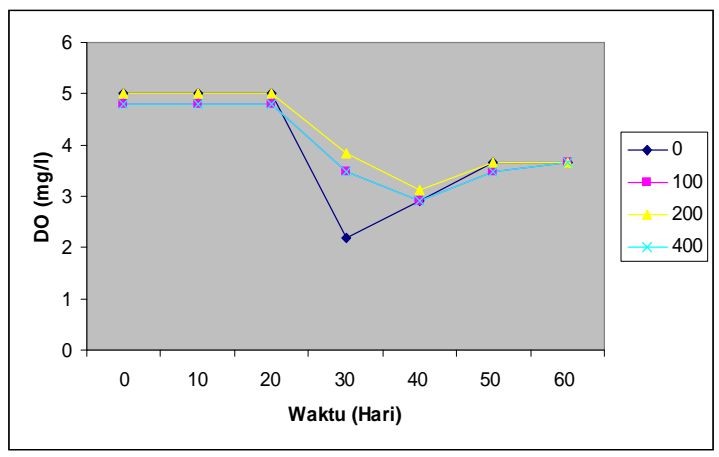

Gambar 10. Kandungan oksigen terlarut berdasarkan atas waktu dan kepadatan.

Figure 10. Disolved oksigen contens during observation based on days and density.

Hasil penelitian menunjukan bahwa dengan laju perambanan yang sama memberikan pengaruh peningkatan pertumbuhan dan mortalitas pada perlakuan kepadatan ikan koan 200 dan 400 ekor lebih besar dibanding kepadatan 100 ekor, mortalitas berturut-turut 5,15 , dan $18,5 \%$. Bila dilihat dari faktor konversi pakan (FCR) pada masing-masing kepadatan ikan koan 100, 200, dan 400 ekor adalah 3,5; 1,99; dan 2,46, maka dapat dikatakan bahwa kepadatan 200 ekor adalah yang paling efektif untuk pengendalian eceng gondok. Perambanan juga menghasilkan pengurangan luas tutupan eceng gondok di permukaan perairan pada kepadatan berturut-turut 100 , 200, dan 400 ekor adalah 0,75; 1; dan 1,68 m².

Kesuburan perairan meningkat dengan adanya perambanan eceng gondok oleh ikan koan karena menurut Hubble \& Harper (2000) produktivitas perairan danau dipengaruhi oleh faktor lingkungan yaitu ketersediaan nutrien $\mathrm{N}$ dan $\mathrm{P}$ sebagai faktor pembatas. Hasil perambanan eceng gondok oleh ikan koan selanjutnya akan disekresikan oleh ikan koan di perairan karena menurut Pipalova (2006) N dan P dari eceng gondok akan menjadi jaringan ikan hanya 42 dan 54\%. Pada lapisan perairan akan terjadi transfer energi bottom-up yaitu adanya ketersediaan pakan eceng gondok yang dicerna ikan koan kemudian disekresikan ke air oleh ikan koan kemudian menjadi nutrien untuk reproduksi fitoplankton (Gliwivicz, 2002). Moss et al. (2002) mengatakan bahwa klorofil-a berhubungan dengan ketersediaan ortofosfat yang $76 \%$ berasal dari sedimen, $4,8 \%$ dari dasar, dan $19,2 \%$ dari air masuk atau keluar danau.

Pengurangan luas tutupan eceng gondok di permukaan perairan berarti membuka luas permukaan untuk dapat menerima sinar matahari, maka proses berproduksi atau fotosintesis akan dapat berjalan, sehingga akan meningkatkan produktivitas perairan. 


\section{KESIMPULAN}

1. Laju perambanan ikan koan dengan kepadatan 100, 200, dan 400 ekor dengan biomassa eceng gondok $10 \mathrm{~kg}$ mempengaruhi peningkatan produktivitas perairan atau kesuburan ( $\mathrm{N}$ dan $\mathrm{P}$ ) dan kelimpahan fitoplankton.

2. Kepadatan ikan koan 200 ekor adalah kepadatan yang paling efektif untuk mengendalikan eceng gondok dibanding kepadatan 100 dan 400 ekor.

\section{DAFTAR PUSTAKA}

Almazan, G. \& C. E. Boyd. 1978. Plankton production and tilapia yield in ponds. Aquaculture. 15: 75-77.

American Public Health Association. 2005. Standard Methods for the Examination of Water and Waste Water. $21^{\text {th }}$ ed. Amer. Publ. Health Association Inc. New York. 1,134 pp.

Bonar, S. A., B. Holding, \& M. Divens. 2002. Effects of triploid grass carp on aquatic plants, water quality, and public satisfaction in Washington State. Nort-American Journal of Fisheries Management. 22: 96-105.

Crawley, M. J. 1983. Herbivory. The Dynamics AnimalPlant Interctions. Studies in Ecology. 10: 437 pp.

Cudmore, Becky, \& N. E. Mandrak. 2004. Biological synopsis of grass carp (Ctenopharyngodon idella) Can. MS Rpt. Fish. Aquat. Sci. 2,705 pp.

El Samman, T. A. \& S. M. A El Ella. 2006. Evaluation applying biological methods to manage aquatic weeds. Tenth International Water Technology Conference. Alexandria. Egypt. 513-525.

Gardner, A. B. 2008. High Density Grass Carp Stocking Effects on a Reservoir Invasive Plant Water Quality, and Native Fishes. Fisheries and Wildlife Sciences. Relight. North Carolina. 78 pp.

Gliwicz, Z. M. 2002. On the different nature of topdown and bottom-up effects in pelagic food weebs. Freshwater Biology. 47: 2,296-2,312.

Hartoto, D. I., K. Kusumadinata, Awalina, \& Yustiawati. 2001. Water hyacinth control using grass carp (Ctenopharyngodon idella) and its related limnological changes in Lake Kerinci, Indonesia. In Dhayat et al. (ed). Proseding Semiloka Nasional: Pengelolaan dan Pemanfaat Waduk dan Danau. Universitas Padjadjaran. 1-40-1-56.
Hickley, P. \& D. Harper. 2002. Fish community and habitat changes in the artificially stocked fishery of Lake Naivasha, Kenya. In Management and Ecology of Lake and Reservoir Fisheries. Edited by I. G Cowx. Fishing News Books an Imprint of Blackwell Science. 242-254.

Hubble, D. S. \& M. Harper. 2000. Top-down biological controls on tropical lake productivity. Lakes and Reservoirs: Research and Management. 5: 187194.

Hulinggi, S. M. 2005. Analisis vegetasi tumbuhan air di perairan Danau Limboto, Kabupaten Gorontalo. Skripsi. Universitas Negeri Gorontalo. 47 pp.

Lembaga Ilmu Pengetahuan Indonesia. 1991. Biologi Perairan Darat. Pusat Penelitian dan Pengembangan Limnologi. Lembaga IImu Pengetahuan Indonesia. Bogor. 163-170.

Moss, B., L. Caravalho, \& J. Plewes. 2002. The lake at llandrindod well-a restoration comedy? Aquatic. Conserv. Mar. Freshw. Ecosyst. 12: 229-245.

Opuszynski, K. \& J. V. Shireman. 1995. Herbivorous Fishes. Culture and Use for Weed Management. Departement of Fisheries and Aquatic Sciences Institute of Food Agricultural Sciences University of Florida. CRC Press. Boca Raton. Ann Arthor London. Tokyo. 223 pp.

Penfound. W. T. \& T. T. Early. 1948. The biology of the water hyacinth. Ecological Monographs. 18: 447-472.

Petr, T. 2000. Interaction between fish and aquatic macrophytes in inland waters a review. FAO Fisheries Technical Paper No. 396. Rome. 185 pp.

Pipalova, I. 2006. A review of grass carp use for aquatic weed control and its impact on water bodies. J. Aquat.Plant.Manage. 44: 1-12.

Pokorny, J. \& J. Kvet. 2004. Aquatic plant and lake ecosystems. In the Lakes. Handbook Vol. 1. Limnology and Limnetic Ecology. ed. By O'Sullivan, P. E. and C. S. Reynolds. Blackwell Publishing. 309-340.

Ryding, S. O. \& W. Rast. 1989. The Control of Eutrophication of Lakes and Reservoirs. Unesco. Paris. 314 pp. 
Sarnita, A. S. 1994. Kajian tentang sumber daya perikanan Danau Limboto, Sulawesi Utara. Prosiding Seminar Perikanan Air Tawar. Balai Penelitian Perikanan Air Tawar. 53-66.

Soeryani, M. 1982. Masalah gulma di Indonesia. Prosiding No. 1: Seminar Perikanan Perairan
Umum. Badan Penelitian dan Pengembangan Pertanian. 33-41.

Wetzel, R. G. 2001. Limnology Lake and River Ecosystem. Third Edition. Academic Press. California. 734 pp. 
Lampiran Tabel 1. Analisis sidik ragam laju perambanan ikan koan terhadap eceng gondok.

Tabel apenddix 1. Analysis of variance grazing rate of grass carp on waterhyacinth

\begin{tabular}{|c|c|c|c|c|c|c|}
\hline ANOVA & & & & & & \\
\hline $\begin{array}{l}\text { Sumber variasi/ } \\
\text { Source of variation }\end{array}$ & SS & $d f$ & MS & $F$ & $P$-value & F crit \\
\hline Rows & 65222,99 & 5 & 13044,6 & 19,1467 & $7,85 \mathrm{E}-05$ & 3,325835 \\
\hline Columns & 448,8711 & 2 & 224,4356 & 0,329424 & 0,726857 & 4,102821 \\
\hline Error & 6812,976 & 10 & 681,2976 & & & \\
\hline Total & 72484,84 & 17 & & & & \\
\hline
\end{tabular}

Lampiran Tabel 2. Analisis sidik ragam laju pertumbuhan ikan koan

Tabel apenddix 2. Analysis of variance growth rate of grass carp

\begin{tabular}{|c|c|c|c|c|c|c|c|}
\hline \multicolumn{8}{|c|}{ ANOVA } \\
\hline \multicolumn{2}{|c|}{$\begin{array}{l}\text { Sumber variasi// } \\
\text { Source of variation }\end{array}$} & SS & $d f$ & MS & $\boldsymbol{F}$ & $P$-value & F crit \\
\hline \multirow{5}{*}{$\begin{array}{l}\text { Rows } \\
\text { Columns } \\
\text { Error } \\
\text { Total }\end{array}$} & & 22818,57143 & 6 & 3803,095 & 5,550228 & 0,00579 & 2,99612 \\
\hline & & 7486,095238 & 2 & 3743,048 & 5,462594 & 0,020569 & 3,885294 \\
\hline & & 8222,571429 & 12 & 685,2143 & & & \\
\hline & & 38527,2381 & 20 & & & & \\
\hline & Column 1 & Column 2 & Colt & & & & \\
\hline Column 1 & 1 & & & & & & \\
\hline Column 2 & 0,528299 & 1 & & & & & \\
\hline Column 3 & 0,383152 & 0,915407 & & & & & \\
\hline
\end{tabular}

